\begin{tabular}{|c|c|}
\hline 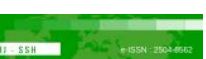 & Malaysian Journal of Social Sciences and Humanities (MJSSH) \\
\hline Malaysian Journal of & Volume 5, Issue 12, December 2020 \\
\hline (MJ-SSH) & e-ISSN : 2504-8562 \\
\hline & $\begin{array}{l}\text { Journal home page: } \\
\text { www.msocialsciences.com }\end{array}$ \\
\hline
\end{tabular}

\title{
Hubungan antara Pembangunan Penerapan Nilai dalam Pendidikan Abad Ke-21 dengan Pembentukan Sahsiah Murid Sekolah Kurang Murid (SKM) Luar Bandar di Sabah
}

\author{
Dg Norizah Ag Kiflee@Dzulkifli1, Roslee Bin Talip1, Soon Singh A/L Bikar Singh', Rosy Talin1, \\ Lee Bih Ni ${ }^{1}$, Tan Choon Keong ${ }^{1}$, Mad Noor B. Madjapuni ${ }^{1}$ \\ ${ }^{1}$ Fakulti Psikologi dan Pendidikan, Universiti Malaysia Sabah (UMS)
}

Correspondence: Dg Norizah Ag Kiflee@Dzulkifli (dndz@ums.edu.my)

\begin{abstract}
Abstrak
Penerapan nilai dalam pendidikan abad ke-21 amat penting bagi membentuk sahsiah murid yang mapan dalam pelbagai aspek seperti yang digariskan dalam Falsafah pendidikan Kebangsaan (FPK). Kajian korelasi ini dijalankan bagi mengkaji hubungan pembangunan penerapan nilai dalam pendidikan abad ke-21 dengan pembentukan sahsiah murid Sekolah Kurang Murid (SKM) luar bandar di Sabah. Kajian ini menggunakan reka bentuk bukan eksperimen dan kaedah kuantitatif. Seramai 209 orang guru SKM dijadikan sampel dalam kajian ini yang dipilih menggunakan kaedah pensamplean rawak mudah. Instrumen soal selidik pula digunakan bagi mengukur variabel-variabel kajian. Data mentah dianalisis menggunakan perisian Statistical Package for Social Sciences (SPSS) dengan menggunakan analisis statistik inferensi yang melibatkan ujian Korelasi Pearson. Hasil analisis menunjukkan terdapat hubungan positif signifikan yang kuat antara pembangunan penerapan nilai dalam pendidikan abad ke21 dengan pembentukan sahsiah murid Sekolah Kurang Murid (SKM) luar bandar di Sabah (r=0.88, $\mathrm{P}<0.05)$. Dapatan kajian ini memberi maklumat berguna berkaitan dengan penerapan nilai dalam pendidikan abad ke-21 dan pembentukan sahsiah murid yang diharap dapat memberikan sumbangan ke arah memperkasakan sistem pendidikan kebangsaan.
\end{abstract}

Kata kunci: penerapan nilai, pembentukan sahsiah murid, Sekolah Kurang Murid (SKM)

\section{The Relationship between Value Approach Development in 21st Century Education and the Forming of the Student' Personality in Rural Under-Enrolled School (SKM) in Sabah}

\begin{abstract}
The implementation of value in 21st century education is crucial to developing sustainable students' personality in various aspects as outlined in the National Education Philosophy (FPK). This correlational study was conducted to examine the relationship of value approach development in 21 st century education with the forming of the student' personality in rural Under-Enrolled School (SKM) in Sabah. The study used non-experimental design and quantitative methods. A total of 209 SKM teachers were selected as samples in this study by using simple random sampling methods. Questionnaire instruments were used to measure the variables. Primary data was analyzed using Statistical Package for Social Sciences (SPSS) software using inferential statistics analysis involving the Pearson Correlation test. The
\end{abstract}


results of the analysis showed that there is a strong positive relationship between the development of value approach in 21 st century education and the forming of the student' personality in rural UnderEnrolled School $(\mathrm{SKM})$ in $\mathrm{Sabah}(\mathrm{r}=0.88, \mathrm{P}<0.05)$. The findings provide useful information relating to the approach of value in 21 st century education and forming of the student' personality which is expected to contribute towards empowering the national education system.

Keywords: value approach, forming of the student' personality, Under-Enrolled School (SKM)

\section{Pengenalan}

Sekolah Kurang Murid (SKM) telah diwujudkan oleh pelbagai negara sebagai satu bentuk usaha dan alternatif bagi memastikan semua murid mendapat akses kepada pendidikan (Nitce et al., 2017). penubuhan sekolah jenis ini turut bertujuan untuk membangunkan perkembangan sahsiah pelajar sama seperti sekolah-sekolah lain di negara kita. Proses pengajaran dan pembelajaran di sekolah bukan sahaja menekankan kepada pencapaian akademik murid, bahkan turut menekankan kepada penerapan nilai kerana peranannya yang sangat signifikan dalam membentuk sahsiah murid secara holistik (Mukhamad Andri et al., 2005).

\section{Pernyataan Masalah}

Usaha pembentukan sahsiah murid ini bukanlah mudah kerana usaha ini sangat bersangkutan dengan sikap murid itu sendiri sama ada terbuka atau tidak terhadap usaha-usaha yang dilaksanakan oleh guru. Sifat-sifat negatif sedia ada murid itu sendiri seperti hadir lewat ke kelas tanpa alasan yang wajar, tidak menyiapkan tugasan yang diberikan oleh guru, membuli rakan, pengaruh daripada rakan sebaya dan sebagainya menyebabkan mereka mempamerkan sahsiah diri yang kurang membanggakan dan bersifat negatif (Yahaya \& Norainiza, 2010). Sifat-sifat negatif murid ini mencerminkan masalah keruntuhan akhlak murid yang sedikit sebanyak akan mempengaruhi pembentukan sahsiah mereka (Mohd Ismail, et al., 2004).

Keruntuhan akhlak yang bersangkutan dengan sahsiah murid ini semakin meruncing dengan perkembangan dunia tanpa sempadan yang membawa budaya luar yang tidak bersesuaian dengan budaya rakyat Malaysia. Masalah ini menjadi semakin kritikal kerana masalah ini bukan sahaja berlaku kepada murid-murid di kawasan bandar bahkan turut menular di kawasan luar bandar atau sekolah di luar bandar yang ada daripadanya terdiri daripada sekolah kurang murid. Kenyataan ini disokong oleh Husin (2011) yang menjelaskan keruntuhan akhlak murid di kawasan luar bandar merupakan suatu perkara yang tidak asing lagi dalam perkembangan dunia tanpa sempadan pada hari ini. Norazri (2015) juga menyatakan masalah keruntuhan akhlak murid bukanlah semestinya berlaku di kawasan bandar sahaja bahkan turut menular di kawasan kehidupan luar bandar yang terkenal dengan adab sopan dan muafakat dan memiliki sahsiah yang baik.

Seterusnya, walaupun pembentukan sahsiah murid akan lebih berkesan jika disampaikan melalui sistem pendidikan formal yang jelas strukturnya yakni sekolah (Abd Rahim, 2001) namun ibu bapa masih memainkan peranan penting dalam pembentukan sahsiah diri murid secara formal dan tidak formal kerana mereka merupakan individu yang paling rapat dengan murid iaitu anak-anak mereka (Mohamad Khairi \& Asmawati, 2010). Oleh itu, ibu bapa perlu menunjukkan usaha-usaha yang sewajarnya dalam membentuk sahsiah anak-anak mereka dan seharusnya mampu mewujudkan suasana rumah yang kondusif dalam mengembangkan sahsiah anak-anak mereka (Indriati, 2010).

Hal ini adalah amat perlu kerana salah satu punca penyelewengan sahsiah ialah faktor kemahiran ibu bapa yang lemah sebagai model contoh yang pertama bagi anak-anak semakin pudar. Kesannya, anakanak tidak dapat mempelajari nilai-nilai murni yang sewajarnya untuk membentuk sahsiah diri mereka (Abdul Rahman, Asmawati, \& Nur Surayyah, 2008). Justeru itu, ibu bapa seharusnya menunjukkan 
contoh sahsiah yang terbaik buat anak-anak mereka supaya anak-anak mereka dapat menyesuaikan dan mempersembahkan diri mereka di sekolah berdasarkan kepada sahsiah yang telah diterapkan kepada mereka bermula di rumah lagi (Latifah, Wan Nasyrudin \& Nurul, 2012).

\section{Objektif Kajian}

Kajian ini dijalankan bagi mencapai objektif-objektif berikut:

i. Mengkaji hubungan pembangunan penerapan nilai pendidikan abad ke-21 dengan pembentukan sahsiah murid Sekolah Kurang Murid (SKM) luar bandar di Sabah.

\section{Hipotesis kajian}

Berikut merupakan hipotesis nol dalam kajian ini:

$\mathrm{Ho}^{1}$ : Tidak terdapat hubungan yang signifikan pembangunan penerapan pendidikan abad ke-21 dengan pembentukan sahsiah murid Sekolah Kurang Murid (SKM) luar bandar di Sabah.

\section{Sorotan Literatur}

\section{Teori Pembelajaran Sosial}

Teori Pembelajaran Sosial (Bandura, 1977) merupakan perluasan daripada teori pembelajaran tradisional atau Teori Tingkah Laku. Teori ini merumuskan bahawa perkara utama yang sering dipelajari oleh murid adalah menerusi pemerhatian terhadap tingkah laku orang lain, khususnya orang yang rapat dan signifikan dengan mereka iaitu guru (Azizi \& Muhamad Jumat, 2017). Oleh itu, dalam teori yang dikemukakan oleh Albert Bandura ini, guru memainkan peranan yang amat penting sebagai model contoh kepada murid-muridnya. Sebagai model contoh dan teladan sudah semestinya peribadi dan apa sahaja yang dilakukan oleh guru akan ditiru oleh para murid.

\section{Model Personaliti Lima Faktor Goldberg}

Model ini telah dikembangkan oleh McCrae dan telah menjadi salah satu model personaliti yang sering dirujuk apabila membuat kajian berkaitan dengan perkembangan personaliti individu (Pervin, Cervone, \& Oliver, 2012; Zaidi, et al., 2013). Para pengkaji juga telah membuktikan model ini merupakan model yang tekal dalam mengkaji personaliti indvidu (Gosling, Rentfrow \& Swan, 2003). Dalam model ini, tret personaliti individu dibahagikan kepada lima dimensi utama iaitu Openness to experience (Keterbukaan atas pengalaman), Conscientiousness (Ketelitian), Extraversion (Ekstraversi), Agreeableness (Kesetujuan/Kesepakatan), dan Neuroticisme (Neurotikisme) (Hardani Widhiastuti, 2014; Zaidi et al., 2014; Adiyono, Purnomo \& Adawiyah, 2018). Dengan merujuk kepada dimensi-dimensi dalam model ini, guru boleh menentukan nilai-nilai murni yang ingin diterapkan kepada murid semasa sesi pembelajaran. Hasil daripada penerapan nilai-nilai murni mengikut dimensi ini seterusnya akan melahirkan sahsiah murid yang juga bercirikan kepada lima dimensi dalam model ini.

\section{Hubungan Pembangunan Penerapan Pendidikan Abad Ke 21 Dengan Pembentukan Sahsiah Murid}

Mohd Komel dalam Mohd AlFaizal (2006) menjelaskan punca permasalahan keruntuhan nilai moral yang berlaku hari ini adalah disebabkan tipisnya iman individu terhadap agama dan nilai-nilai baik atau yang diistilahkan sebagai nilai-nilai murni. Maka tidak dapat dinafikan bahawa berlakunya gejala negatif 
dalam kalangan remaja kini adalah berpunca dari kurangnya nilai-nilai murni dalam diri atau atas tanggungjawab diri individu itu sendiri. Melalui pembentukan nilai yang dipegang, murid akan bertindak berdasarkan nilai yang diberikan kepada mereka. Tanpa penerapan nilai murni para murid akan mudah terpengaruh dengan unsur-unsur negatif melalui perubahan zaman yang semakin berkembang di negara ini. Sekiranya pertimbangan nilai murni berkurangan maka ia akan mempengaruhi cara pemikiran, maka perkara yang tidak sepatutnya boleh berlaku kepada diri individu tersebut dan juga orang disekeliling mereka.

Omar (2008) pula menjelaskan pendidikan nilai sangat penting bagi membanteras gejala dan masalah sosial yang dihadapi oleh masyarakat dan negara. Oleh yang demikian, penerapan nilai-nilai murni ini perlu dipupuk kepada pelajar sejak dari alam persekolahan lagi. sebagaimana yang dinyatakan oleh Ibrahim Ahmad (2003), pendidikan dan pengetahuan agama merupakan medium terpenting dalam membentuk jati diri serta mampu membentuk spiritual yang murni dalam kalangan pelajar. Selain itu, kurikulum pendidikan berperanan sebagai satu mekanisme bagi menanamkan sifat-sifat nilai-nilai murni, akhlak, dan tingkah laku yang baik. Kasran (2011), juga menyebut nilai murni adalah salah satu komponen yang membentuk budaya dan berubah mengikut masa dan faktor persekitaran. Oleh yang demikian, penerapan nilai-nilai murni ini perlu menjadi satu matlamat dalam proses pendidikan bagi melahirkan generasi yang mempunyai sahsiah yang mulia.

Dapatan kajian Yakcop Jantan dan Chua (2007) berkaitan dengan kompetensi guru dalam membentuk sahsiah pelajar sekolah menunjukkan terdapat hubungan yang tinggi antara penerapan nilai dalam pendidikan dengan pembentukan sahsiah murid. Abdullah Sani, Abdul Rashid dan Abdul Ghani (2007) pula mendapati guru merupakan pihak yang bertanggungjawab membentuk budaya sekolah yang positif di mana hasilnya terbentuk dalam lingkungan pelajar yang dikaitkan sebagai produk sesebuah sekolah.

Hasil kajian ini juga didapati menyokong dapatan kajian Anita, Mohd Isa dan Mohd Mahzan (2014) yang mendapati proses memupuk nilai-nilai murni mempunyai perkaitan dengan pengetahuan yang dimilikinya di mana pengetahuan tentang kurikulum dan pedagogi nilai-nilai murni merupakan prasyarat dalam proses penerapan nilai-nilai murni tersebut. Hasil kajian ini juga didapati selaras dengan kajian Mohd Khairi dan Asmawati (2010) yang menegaskan bahawa memang menjadi tanggungjawab guru untuk menerapkan nilai-nilai sahsiah dengan berkesan agar pelajar dapat dibentuk menjadi masyarakat yang bermoral, memiliki tahap sosial dan kerohanian yang tinggi.

Selain itu, Ali Suradin dan Eni Eryanti (2005) turut menyokong penyataan ini dengan menjelaskan murid yang mengamalkan nilai-nilai murni cenderung untuk tidak melakukan masalah disiplin dan memiliki sahsiah yang lebih baik. Tambahan lagi, Kaur (2013) juga menjelaskan pendidikan nilai mempunyai hubungan yang positif dengan pembentuk sahsiah murid. Pengkaji menjelaskan, pendidikan di sekolah sememangnya harus menerapkan nilai-nilai murni terhadap murid kerana nilai merupakan salah satu kriteria penting terhadap pembentukan manusia. Seterusnya, pendidikan nilai amat diperlukan untuk membentuk sahsiah diri murid, khususnya dalam dunia modenisasi yang telah mengikis nilai-nilai diri murid. Penulis menambah nilai-nilai murni mempunyai kesan yang menyeluruh terhadap perkembangan individu. Oleh itu, sekiranya nilai yang ditunjukkan atau dihayati adalah baik maka, kehidupan individu akan menjadi lebih bermakna kerana nilai-nilai tersebut membentuk sahsiah yang baik dalam kehidupan seharian.

\section{Metod Kajian}

\section{Reka bentuk, Kaedah, dan Teknik Kajian}

Reka bentuk yang dipilih ialah reka bentuk bukan eksperimen. Kaedah kajian yang dipilih pula ialah kaedah kuantitatif dengan menggunakan tinjauan bertepatan dengan pendapat Creswell (2009) yang menjelaskan kaedah tinjauan sesuai digunakan bagi kajian yang menggunakan reka bentuk bukan eksperimen. Teknik yang digunakan ialah teknik soalan berasaskan instrumen soal selidik untuk mendapatkan maklumat daripada responden. Instrumen soal selidik yang digunakan dalam kajian ini 
terdiri daripada tiga bahagian iaitu Bahagian A (Demografi Responden), Bahagian B (Penerapan Nilai dalam Pendidikan abad ke 21 - 20 item), dan Bahagian C (Pembentukan Sahsiah Murid - 10 item). Data mentah dianalisis menggunakan perisian Statistical Package for Social Sciences (SPSS) dengan menjalankan ujian statistik inferensi Korelasi Pearson.

\section{Lokasi Kajian}

Kajian ini dijalankan di daerah Ranau, Sabah sahaja. Kajian ini hanya dijalankan di daerah ini sahaja disebabkan oleh beberapa faktor iaitu kekangan masa, penularan wabak Covid-19 yang menyukarkan kajian secara menyeluruh di seluruh sabah dan kebanyakan Sekolah Kurang Murid terletak di daerah Ranau iaitu sebanyak 35 buah sekolah.

\section{Populasi dan Sampel Kajian}

Populasi kajian adalah seramai 459 orang guru Sekolah Kurang Murid di daerah Ranau. Namun begitu, daripada jumlah ini, hanya 209 orang guru sahaja yang dipilih untuk menjadi sampel dalam kajian ini. Kaedah pensampelan yang digunakan dalam kajian ini adalah kaedah pensampelan rawak mudah yang bermaksud setiap guru daripada populasi iaitu guru di Sekolah Kurang Murid luar bandar di Ranau mempunyai peluang sama rata untuk dipilih sebagai responden kajian bertepatan dengan pendapat Merican (2009), menerusi pensampelan rawak mudah, setiap elemen dalam populasi mempunyai peluang yang sama untuk dipilih sebagai responden. Dalam menentukan saiz sampel untuk dijadikan responden kajian, jadual penentuan saiz sampel mengikut Krejcie dan Morgan (1970) telah dirujuk, Berdasarkan jadual penentuan saiz sampel Krejcie dan Morgan (1970), telah ditetapkan berapakah jumlah sampel yang perlu diambil daripada jumlah populasi. Bagi menambahkan lagi kebolehpercayaan bilangan sampel yang dipilih adalah mencukupi, pengiraan jumlah bilangan sampel yang diperlukan mengikut formula pengiraan saiz sampel Cochran (1977) juga telah dilaksanakan (Bartlett, Kotrlik, \& Higgins, 2001).

\section{Kajian Rintis}

Chua (2006) menyatakan kajian rintis dikenali sebagai kajian mini bagi sesuatu kajian penuh. Sebelum menjalankan kajian sebenar, kajian rintis telah dilaksanakan ke atas 100 orang guru Sekolah Kurang Murid luar bandar di daerah Ranau Sabah. Jumlah ini bertepatan dengan pendapat Connely (2008) yang menyarankan jumlah sampel bagi kajian rintis adalah sebanyak 10 peratus daripada sampel sebenar kajian. Oleh itu, sampel kajian ini melebihi jumlah sampel kajian rintis yang diperlukan dalam kajian ini. Analisis kesahan item dan analisis kebolehpercayaan telah dijalankan bagi item penerapan nilai dalam pendidikan abad ke $21(\alpha=0.91)$ dan pembentukan sahsiah murid $(\alpha=0.82)$. Analisis kesahan item menunjukkan kesemua item mempunyai nilai faktor (factor loading) melebihi 0.40 seperti yang dijelaskan oleh Hair, Black, Babin, dan Anderson (2010), nilai faktor muatan lebih daripada 0.40 sesuai untuk digunakan dalam kajian.

\section{Hasil Kajian}

\section{Ho1: Tidak Terdapat Hubungan yang Signifikan Pembangunan Penerapan Nilai Pendidikan Abad ke-21 dengan Pembentukan Sahsiah Murid Sekolah Kurang Murid (SKM) Luar Bandar di Sabah}

Berdasarkan dapatan ujian Korelasi Pearson dalam jadual 1, terdapat hubungan positif yang kuat antara variabel kajian $(\mathrm{r}=0.88),(\mathrm{P}=0.00)$ lebih kecil daripada aras signifikan yang ditetapkan $(\mathrm{P}<0.05)$. Dengan itu, hipotesis nol yang menyatakan tidak terdapat hubungan yang signifikan pembangunan penerapan nilai pendidikan abad ke-21 dengan pembentukan sahsiah murid Sekolah Kurang Murid (SKM) luar bandar di sabah adalah ditolak. 


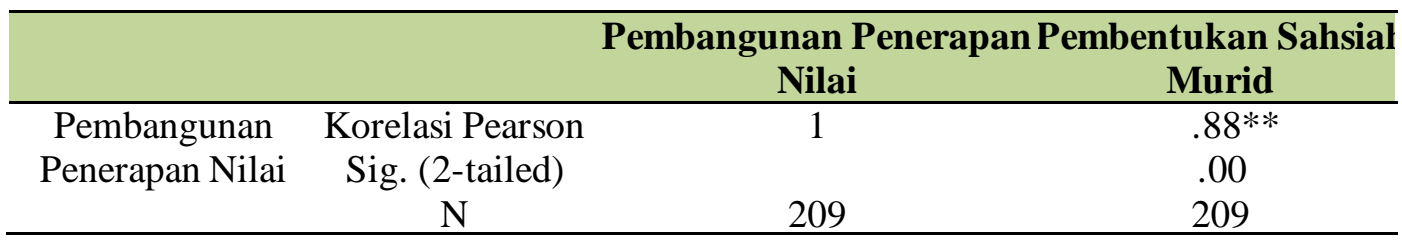

\section{Perbincangan Kajian}

Dapatan kajian ini selari dengan hasil kajian Mohamad Khairi et al. (2017) yang menjelaskan pembentukan nilai murni sangat penting dalam membentuk sahsiah murid sama ada semasa berada di sekolah atau di luar sekolah. Nilai-nilai murni ini dapat membezakan sahsiah murid yang mana secara langsung boleh ditonjolkan menerusi percakapan, tindakan, dan pemikiran.

Norazri (2015) pula menegaskan pendidikan nilai memainkan peranan penting dalam membina nilainilai positif dalam diri murid. Oleh itu, penerapan nilai amat penting dalam membentuk sahsiah murid yang jitu dan seimbang daripada segi akademik dan akhlak. Akhirnya, dengan pendidikan yang menerapkan nilai-nilai murni dalam proses pengajaran dan pembelajaran ini akan melahirkan pelajar yang mempunyai sahsiah yang mulia.

Mohamad Khairi (2014) turut menjelaskan pendidikan nilai sememangnya satu usaha yang perlu untuk dilaksanakan kerana penerapan nilai murni dalam pembelajaran amat mustahak, terutama bagi menyediakan murid yang mempunyai ketahanan diri yang kukuh. Murid yang dididik melalui sistem persekolahan ini mestilah mampu menghadapi cabaran semasa dan juga cabaran masa depan. Penerapan nilai-nilai murni ini akan menjamin pembentukan peribadi dan sahsiah diri murid yang utuh, kental, dan padu. Selain itu, penulis menyatakan penerapan nilai dalam pendidikan mampu melahirkan murid yang memiliki sahsiah yang seimbang seperti yang terkandung dalam Falsafah Pendidikan Kebangsaan.

Seterusnya, dapatan kajian ini juga disokong oleh pengkaji luar negara. Kaur (2013) yang menjelaskan pendidikan nilai mempunyai hubungan yang positif dengan pembentuk sahsiah murid. Pengkaji menjelaskan, pendidikan di sekolah sememangnya harus menerapkan nilai-nilai murni terhadap murid kerana nilai merupakan salah satu kriteria penting terhadap pembentukan manusia. Seterusnya, Patil (2013) juga menjelaskan pendidikan nilai amat diperlukan untuk membentuk sahsiah diri murid, khususnya dalam dunia modenisasi yang telah mengikis nilai-nilai diri murid. Penulis menambah nilainilai murni mempunyai kesan yang menyeluruh terhadap perkembangan individu. Oleh itu,sekiranya nilai yang ditunjukkan atau dihayati adalah baik maka, kehidupan individu akan menjadi lebih bermakna kerana nilai-nilai tersebut membentuk sahsiah yang baik dalam kehidupan seharian.

Dapatan Nurlaela (2013) juga selari dengan dapatan kajian ini. pengkaji menjelaskan penerapan nilai mempunyai hubungan dengan tingkah laku murid. Tingkah laku ini seterusnya akan membentuk sahsiah diri murid tersebut. Oleh itu, pengkaji menekankan bahawa pendidikan nilai yang membentuk sahsiah murid boleh membantu murid untuk membezakan perkara yang baik dan buruk, menyelesaikan masalah dan memiliki masa hadapan yang lebih cerah. Dapatan ini diperkukuh lagi dengan pendapat Smith dan Spranger yang menekankan bahawa nilai merupakan elemen yang mewarnai sahsiah murid (Atmadi, 2013).

\section{Implikasi Kajian}

\section{Implikasi terhadap Teori dan Model}

Teori Pembelajaran Albert Bandura 1977 dan Model Personaliti Lima Faktor Goldberg yang digunakan dalam kajian ini terbukti sesuai dengan isu yang dikaji. 


\section{Implikasi terhadap Pengamalan}

Dapatan kajian ini dapat memberi gambaran kepada Kementerian Pelajaran Malaysia (KPM), Jabatan Pelajaran Negeri Sabah (JPNS), pihak pentadbir sekolah dan para guru tentang hubungan penerapan pendidikan nilai dalam pendidikan abad ke-21 Sekolah Kurang Murid di daerah Ranau Sabah.

\section{Implikasi terhadap Penyelidikan}

Instrumen soal selidik dalam kajian ini sesuai digunakan untuk mengkaji tentang penerapan nilai dalam pendidikan abad ke-21 dan pembentukan sahsiah murid.

\section{Kesimpulan}

Kesimpulannya, kajian ini telah membuktikan penerapan nilai dalam pendidikan abad ke-21 dengan pembentukan sahsiah murid Sekolah Kurang Murid luar bandar di Sabah mempunyai hubungan dan pengaruh yang positif. Oleh itu, kajian-kajian yang berkaitan dengan penerapan nilai dan pembentukan sahsiah murid perlulah dititikberatkan kerana kedua-dua aspek ini amat mempengaruhi kejayaan Kementerian untuk melahirkan murid yang seimbang seperti yang dijelaskan dalam Falsafah Pendidikan Kebangsaan. Kajian berkaitan Sekolah Kurang Murid juga perlu diperbanyakkan khususnya yang berkaitan dengan penerapan nilai dan pembentukan sahsiah murid. Justeru itu, pihak-pihak yang bertanggungjawab bolehlah menggunakan dapatan kajian ini untuk menambah baik sistem pendidikan di negara kita.

\section{Rujukan}

Abd. Rahim Abd. Rashid. (2001). Nilai-Nilai Murni Dalam Pendidikan: Menghadapi Perubahan dan Cabaran Alaf Baru. Kuala Lumpur: Utusan Publications \& Distributors Sdn. Bhd.

Abdul Rahman Md. Aroff, Asmawati Suhid \& Nur Surayyah Madhubala Abdullah. (2008). Pendidikan Nilai dan Pembinaan Watak. Pendidikan di sekolah: isu dan cabaran. Serdang: Universiti Putra Malaysia.

Abdullah Sani Yahya, Abdul Rashid Mohamed, \& Abdul Ghani Abdullah. (2007). Guru Sebagai Pemimpin. Kuala Lumpur: PTS Professional.

Adiyono, A., Purnomo, R., \& Adawiyah, W. (2018). Pengaruh Kepribadian Lima Faktor Terhadap Kesuksesan Karir. Jurnal Bisnis Dan Ekonomi, 24(2), 162-176.

Ali Ali Bin Suradin dan Eni Eryanti Yusoff. (2005). Penghayatan Nilai-Nilai Murni Ke Arah Pembentukan Disiplin Pelajar. Prosiding Seminar Pendidikan JPPG.

Anita Abu Hasan, Mohd Isa Hamzah \& Mohd Mahzan Awang. (2014). Inculcating Noble Values for Pre-Service Teachers. International Education Studies, 7(11), 111-119.

Atmadi, G. 2013. The implementation of corporate communication based on local wisdom in facing globalization. Prosiding the 5th International Conference on Indonesian Studies: "Ethnicity and Globalization”.189-204.

Azizi Yahaya \& Muhamad Jumat Aliju. (2017). Teori-teori Tingkah Laku Negatif. Fakulti Pendidikan, Universiti Teknologi Malaysia.

Bartlett, J. E., Kotrlik, J. W., \& Higgins, C. C. (2001). Organizational Research: Determining Appropriate Sample Size in Survey Research. Informational Technology, Learning, and Performance Journal, 19(1), 43-50.

Chua, Y. P. (2006). Kaedah Penyelidikan. Kuala Lumpur: McGraw Hill Companies.

Connelly, L. M. (2008). Pilot studies. Medsurg Nursing, 17(6), 411-412.

Creswell, J. W. (2008). Educational Research: Qualitative, Quantitative, and Mixed Methods Approaches (2 $2^{\text {nd }}$ ed.). Thousand Oaks: Sage Publication Gosling, Rentfrow dan Swan, 2003.

Hair, J. F., Black, W. C., Babin, B. J., \& Anderson, R. E. (2010). Multivariate Data Analysis (7 ${ }^{\text {th }}$ ed.). New Jersey: Prentice Hall. 
Hardani Widhiastuti. (2014). Big Five Personality Sebagai Predictor Kreativitas Dalam Meningkatkan Kinerja Anggota Dewa. Jurnal Psikologi, 41(1), 115-133.

Husin Junoh. (2011). Faktor keruntuhan akhlak remaja Islam luar bandar di Daerah Kota Tinggi, Johor. Tesis PhD. Universiti Malaya.

Ibrahim Bin Ahmad. (2003). Profesion Keguruan Pilihan Terakhir?: Suatu Tinjauan. Seminar Memperkasakan Sistem Pendidikan. Puteri Pan Pacific, Johor Bahru. 19-21 Oktober 2003.

Kasran, M. H. (2011). Nilai-Nilai Sejagat Dalam Pengisian Kurikulum Bahasa Malaysia. Prosiding Seminar Majlis Dekan-Dekan Pendidikan IPTA 2011. Institut Pendidikan Guru Kampus Rajang, Sarawak.

kaur, J. (2013). An Analysis of The Importance and Role of Value Based Education: The Need of Hour. Journal of Advances and Scholary Researches in Allied Education, 5(11), 1-6.

Mohamad Khairi Othman, Mohd Zailani Mohd Yusoff, Alias Puteh \& Nurfasihah Roslan (2017). Permasalahan Dan Cabaran Guru Dalam Membentuk Nilai Pelajar Di Sekolah Menengah. Jurnal Sultan Alauddin Sulaiman Shah, 1-10.

Krejcie, Robert V. \& Morgan Daryle W. (1970). Determining Sample Sizes for Research Activities. Educational and Psychological Measurement, 607-610.

Latifah Abdul Majid, Wan Nasyrudin Wan Abdullah, \& Nurul Hidayah Ahmad Zakhi. (2012). Penerapan Nilai Murni Dan Pembentukan Jati Diri Kanak-Kanak Prasekolah Melalui Penggunaan Multimedia. Jurnal Hadhari, 51-65.

Marican, S. (2006). Penyelidikan Sains Sosial-Pendekatan Pragmatik. Selangor: Edusystem Sdn Bhd. Mohamad Khairi Othman. (2014). Hubungan Penerapan Nilai Murni Dalam Pengajaran Bahasa Melayu Dengan Penghayatan Nilai Murni Pelajar. Journal of Human Development and Communication, 3, 81-92.

Mohd AlFaizal che Alui. (2006). Pengamalan Nilai-Nilai Murni Di Kalangan Pelajar Tingkatan 4 Sekolah Menengah Kebangsaan Taman Universiti (2) Yang Diamalkan Dalam Kehidupan Seharian. Tesis. Universiti Teknologi Malaysia.

Mohd Ismail Mustari, Robiah Ya'akob, Syarifah @ Noriana Chik, Kamarul Azmi Jasmi \& Ahmad Kilani Mohamed. (2004). Permasalahan Ibu Tunggal dalam Melaksanakan Tanggungjawab Pendidikan Anak-anak: Satu Kajian Kawasan Sura, Dungun, Terenggannu. Seminar Pembangunan Keluarga, 1-6.

Mohamad Khairi Othman. (2014). Hubungan Penerapan Nilai Murni Dalam Pengajaran Bahasa Melayu Dengan Penghayatan Nilai Murni Pelajar. Journal of Human Development and Communication, 3 , 81-92.

Mukhamad Andri Setiawan, Army Widyatusti \& Aulia Nurhuda. (2005). Pengaruh Komputer Pada Perkembangan Psikologi Anak. Seminar Nasional Aplikasi Teknologi Informasi.

Nitce Isa Medina Machmudi Isa, Azlin Norhaini Mansor \& Jamalul Lail Abdul Wahab. (2017). Cabaran Kepimpinan Instruksional Guru Besar Di Sekolah Kurang Murid. Prosiding semiunar pendidikan serantau ke VIII. Anjuran Fakulti Pendidikan, Universiti Kebangsaan Malaysia \& Fakultas Keguruan \& Ilmu Pendidikan, Universitas Riau.

Norazri Mohd Zaidin. (2015). Penerapan Nilai-Nilai Murni Dalam Proses Pengajaran Dan Pembelajaran Ke Arah Pembentukan Sahsiah Pelajar Di Kolej Kemahiran Tinggi Mara. Tesisi Sarjana. Fakulti Pendidikan Teknik Dan Vokasional. Universiti Tun Hussien Onn Malaysia.

Nurlaela Sari. (2013). The Importance of Teaching Moral Values to The Student. Journal of English And Education, 1(1), 154-162.

Omar, A. (2008). Penerapan Nilai-Nilai Murni Dalam Kalangan Pelajar Sarjana Muda Pendidikan Teknik Dan Vokasional Semasa Menjalankan Amali Di Makmal, Universiti Tun Hussein Onn Malaysia: Tesis Sarjana. Universiti Tun Hussein Onn Malaysia.

Patil, V. (2013). "Patriarchy to Intersectionality: A Transnational Feminist Assessment of How Far We've Really Come." Sign:Journal of Women in Culture and Society, 38(4), 947-867.

Pervin, L. A., Cervone, D., \& Oliver, P. J. 2012. Psikologi kepribadian: Teori dan Penelitian ( $\left.9^{\text {thed. }}\right)$. Jakarta: Kencana Prenada Media Group.

Yahaya Buntat \& Norainiza. (2010). Faktor-Faktor Yang Mempengaruhi Masalah Ponteng Kelas Di Kalangan Pelajar Di Kolej Kemahiran Belia Nasional, Pontian. Fakulti pendidikan. Universiti Teknologi Malaysia.

Yakcop Jantan \& Chua Yan Piaw. (2017). Kompetensi Guru Dalam Membentuk Sahsiah Pelajar Sekolah. Jurnal Kepimpian Pendidikan, 4(3), 1-12. 
DOI: https://doi.org/10.47405/mjssh.v5i12.57 7

Zaidi, N. R., Wajid, R. A., Zaidi, F. B. \& Zaidi, G. B. (2013). The Big Five Personality Traits and Their Relationship with Work Engagement Among Public Sector University Teachers of Lahore. African Journal of Business Management, 7(15), 1344-1353. 